\title{
Incidence of Delayed Bleeding among Patients Continuing Antithrombotics during Gastric Endoscopic Submucosal Dissection
}

\author{
Naomi Kakushima, Hiroyuki Ono, Kohei Takizawa, Masaki Tanaka, Noboru Kawata, \\ Masao Yoshida, Katsuyuki Murai, Yohei Yabuuchi, Yoshihiro Kishida, Sayo Ito, \\ Kenichiro Imai, Kinichi Hotta, Hirotoshi Ishiwatari and Hiroyuki Matsubayashi
}

\begin{abstract}
:
objective In patients continuing antithrombotics, delayed bleeding after gastric endoscopic submucosal dissection (ESD) is a severe complication. Vonoprazan (VPZ) exerts a rapid, potent, and long-lasting antacid effect compared with traditional proton-pump inhibitors (PPIs). This study aimed to compare the incidence of delayed bleeding after gastric ESD between the use of VPZ and PPIs in patients continuing antithrombotics.

Methods In this retrospective analysis, we examined 71 patients with 101 lesions treated with traditional PPIs (PPI group) and 59 patients with 90 lesions treated with VPZ (VPZ group). After 2 days (day 0 and 1) of intravenous PPI administration, either an oral PPI or VPZ was administered from postoperative day 2 to 8 weeks after ESD. We assessed the incidence of overall delayed bleeding as well as bleeding that occurred from day 2 until 8 weeks after ESD.

Results There was no significant difference in the use of antithrombotic agents between the groups. Overall delayed bleeding occurred 13 times (18\%) in 9 patients in the PPI group and 18 times (31\%) in 17 patients in the VPZ group ( $\mathrm{p}=0.10)$. Bleeding from day 2 until 8 weeks after ESD occurred 12 times (17\%) in 9 patients in the PPI group and 8 times (14\%) in 8 patients in the VPZ group.

Conclusion Even with a potent antacid agent, such as VPZ, the incidence of delayed bleeding was high in patients undergoing ESD with continuous antithrombotic agents.
\end{abstract}

Key words: endoscopic submucosal dissection, stomach, bleeding, antithrombotic agents

(Intern Med 58: 2759-2766, 2019)

(DOI: 10.2169/internalmedicine.2754-19)

\section{Introduction}

At present, many patients with early gastric cancer are treated with endoscopic submucosal dissection (ESD) because of the permeation of mass-screening programs and early detection of the disease in East Asia (1). ESD is less invasive than surgery; however, two major complications, namely gastric perforation and bleeding, are associated with this approach $(1,2)$. Efforts to reduce the risk of bleeding after ESD have been made using prophylactic coagulation of vessels immediately after ESD (3) and proton-pump inhibi- tors (PPIs) during and after ESD (4). However, the risk of bleeding remains a critical clinical problem, especially in patients taking antithrombotic agents, such as antiplatelet and anticoagulant agents (5-12).

In Japan, the number of patients taking antithrombotic agents for concomitant diseases is witnessing an upsurge because of the rapidly aging population. In these patients, whether to continue or discontinue antithrombotic agents during the period of endoscopic procedures is determined on the basis of the individual risk of cardiovascular or neurovascular thrombotic events and the risk of bleeding associated with the endoscopic procedure $(13,14)$. As the rate of 


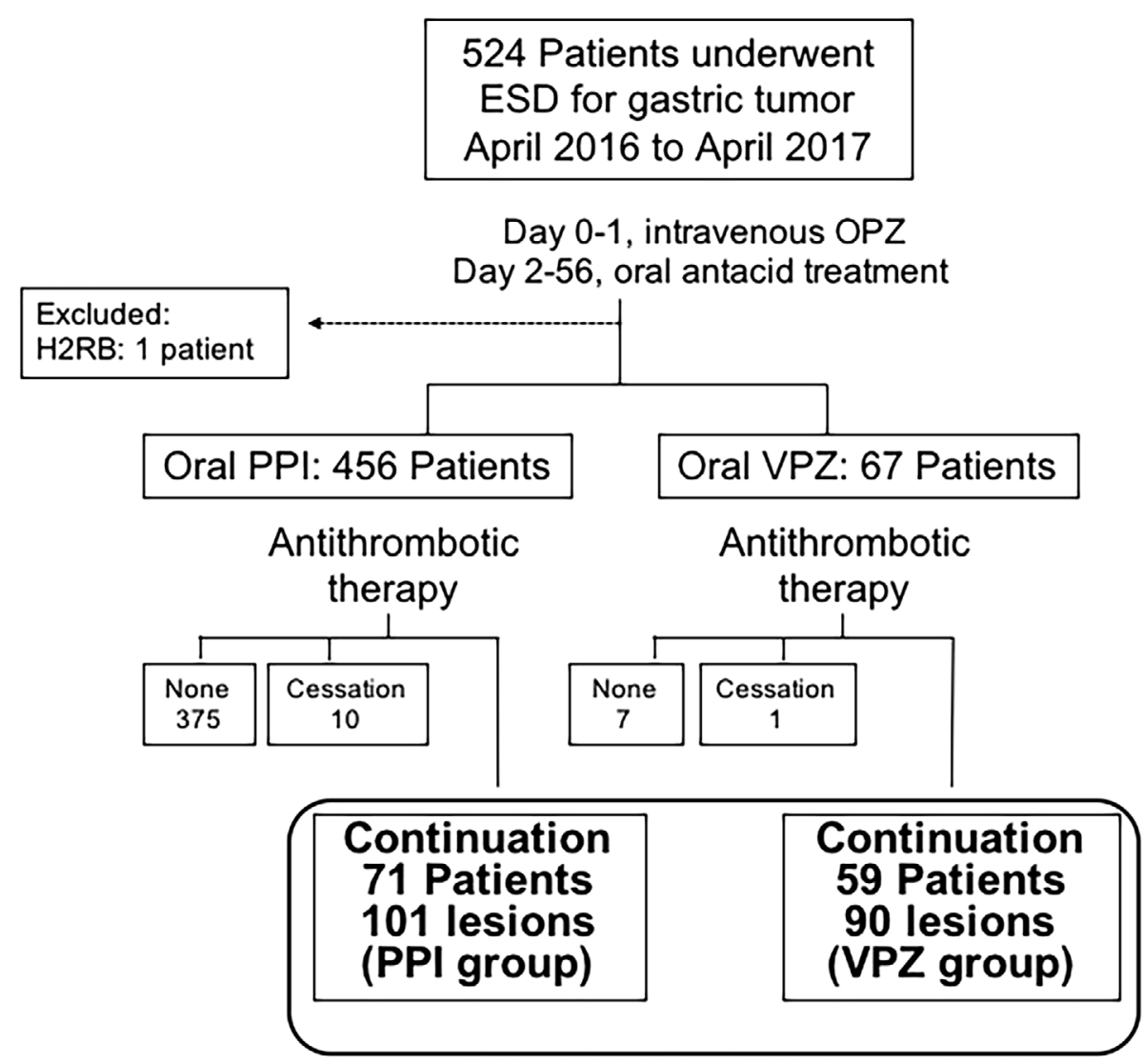

Figure 1. Patient flow. ESD: endoscopic submucosal dissection, OPZ: omeprazole, H2RB: histamine 2-receptor blocker, PPI: proton-pump inhibitor, VPZ: vonoprazan

performing ESD without cessation of antithrombotic agents is on the rise, a high incidence of bleeding after ESD has been reported in patients taking antithrombotic agents $(5-7,11,12)$.

Vonoprazan (VPZ) is a potassium-competitive acid blocker that exerts a rapid, potent, and long-lasting inhibition of gastric acid secretion compared with traditional PPIs (15). Research has revealed that healing of gastric ulcers created by ESD is as good or better in patients treated with VPZ than in those treated with traditional PPIs (16-26). However, most previous studies have examined patients not taking antithrombotic agents or who stopped taking the agents during ESD. Thus, the efficacy of VPZ in ESD among patients continuing antithrombotic agents remains unclear.

This study aims to compare the incidence of delayed bleeding after gastric ESD between the use of VPZ and traditional PPIs in patients continuing antithrombotic therapy.

\section{Materials and Methods}

\section{Patients and study design}

In this retrospective, single-centre study, we conducted a chart-based investigation of 524 consecutive patients who were treated with ESD at a prefectural cancer center from April 2016 to April 2017. The inclusion criteria in this study comprised patients with a preoperative diagnosis of gastric epithelial neoplasms who underwent ESD with continuous antithrombotic agents and were treated with oral PPIs or VPZ after ESD. We excluded patients not taking antithrombotic agents or those who discontinued antithrombotic agents before ESD from the analysis. In addition, we excluded one patient who was treated with a histamine 2receptor blocker without a PPI or VPZ. Based on the antacid treatment used after ESD, all patients were categorized into 2 groups as follows: (a) 71 patients with 101 gastric tumours treated with a traditional PPI (PPI group); and (b) 59 patients with 90 gastric tumours treated with VPZ (VPZ group; Fig. 1). This study protocol was approved by the Ethics Committee of our hospital, and all patients provided their written informed consent for ESD under continuous antithrombotic agent administration.

\section{ESD procedure and management after ESD}

In all patients, ESD was performed using an IT knife-2 (KD-611L; Olympus, Tokyo, Japan), an endoscope with a water-jet function (GIF-Q260J; Olympus), and a highfrequency generator (VIO300D; ERBE Elektromedizin, Tubingen, Germany), as described previously (27). Immediately after tumour resection, visible vessels were coagulated using hot biopsy forceps or an IT knife-2. In some patients, however, ulcer protection was performed by the closure of the ESD ulcer with endoclips (full or partially; closure group) 
Table 1. Baseline Patients' Characteristics.

\begin{tabular}{|c|c|c|c|c|}
\hline Patient characteristics & & $\begin{array}{l}\text { PPI group } \\
71 \text { patients }\end{array}$ & $\begin{array}{l}\text { VPZ group } \\
59 \text { patients }\end{array}$ & $\mathrm{p}$ \\
\hline Age, year, median \pm SD & & $77 \pm 6$ & $76 \pm 7$ & 0.8 \\
\hline Sex, male, n (\%) & & $56(79)$ & $52(88)$ & 0.06 \\
\hline \multirow[t]{3}{*}{ Comorbidity, n (\%) } & Hypertension & $57(80)$ & $45(76)$ & 0.57 \\
\hline & Diabetes mellitus & $9(13)$ & $19(32)$ & 0.007 \\
\hline & Renal failure on hemodialysis & $0(0)$ & $1(1.6)$ & 0.2 \\
\hline \multirow[t]{4}{*}{ Reasons for antithrombotic therapy, n (\%) } & Ischemic heart disease & $21(30)$ & $17(31)$ & 0.92 \\
\hline & Arrhythmia & $10(14)$ & $12(20)$ & 0.34 \\
\hline & Cerebrovascular disease & $17(24)$ & $22(37)$ & 0.1 \\
\hline & Others & $8(11)$ & $2(3)$ & 0.09 \\
\hline \multirow[t]{4}{*}{ Type of antithrombotic agents, n (\%) } & Antiplatelet monotherapy & $46(65)$ & $29(49)$ & 0.07 \\
\hline & Antiplatelet dual therapy & $10(14)$ & $15(25)$ & 0.1 \\
\hline & Anticoagulant monotherapy & $11(15)$ & $11(19)$ & 0.6 \\
\hline & Combination of antiplatelet and anticoagulant & $4(6)$ & $4(7)$ & 0.7 \\
\hline \multirow[t]{2}{*}{ Number of tumors, $\mathrm{n}(\%)$} & 1 & $53(75)$ & $41(69)$ & 0.5 \\
\hline & $2-6$ & $18(25)$ & $18(31)$ & \\
\hline
\end{tabular}

SD: standard deviation, n: number, PPI: proton-pump inhibitor, VPZ: vonoprazan

or by covering an ulcer with a polyglycolic acid (PGA) sheet. On the day after ESD (day 1), a second-look endoscopy, complete blood cell count, and chest X-ray were performed. Eating was prohibited on the day of and day following ESD, and intravenous omeprazole (40 mg/day) was administered. From day 2, a soft-food diet was started, and either oral VPZ (20 mg daily) or PPI (20 mg rabeprazole or $30 \mathrm{mg}$ lansoprazole or $20 \mathrm{mg}$ esomeprazole daily; certified dose in Japan) was administered until 8 weeks after ESD. Of note, there were no definite criteria for selecting PPI or VPZ, and either was selected at the discretion of the principal physician before the ESD procedure.

\section{Outcome measurement}

In this study, the primary outcome measurement was the difference in the incidence of delayed bleeding between patients treated with VPZ and traditional PPI. We defined delayed bleeding as follows: patient with overt hematemesis, melena, bloody stool after ESD; whose bleeding was confirmed on an endoscopic examination or required haemostasis or transfusion; or whose haemoglobin level decreased by $\geq 2 \mathrm{~g} / \mathrm{dL}$. The overall incidence of delayed bleeding and bleeding that occurred from day 2 until 8 weeks after ESD was compared between the groups. Secondary outcomes were the difference in the delayed bleeding rates according to tumour location, number of tumours, curability of ESD, and ulcer protection.

The curability of ESD was determined per the guidelines of the Japan Gastroenterological Endoscopy Society and Japanese Gastric Cancer Association (28). ESD was considered curative when en bloc resection revealed negative horizontal or vertical margins, with no lymphovascular infiltration, and the lesion met any of the following conditions: (a) differentiated type pT1a, ulceration (UL)(-); (b) differentiated type pT1a, $\leq 30 \mathrm{~mm}, \mathrm{UL}(+)$; (c) differentiated type pT1 b $(<500 \mu \mathrm{m}), \leq 30 \mathrm{~mm}$; and (d) undifferentiated type pT1a, $\leq 20 \mathrm{~mm}$, UL(-).

Antithrombotic agents were defined as antiplatelet drugs (e.g., low-dose aspirin, cilostazol, thienopyridine derivatives, or others) or anticoagulants (e.g., warfarin or direct oral anticoagulants, including dabigatran, rivaroxaban, apixaban, and edoxaban).

\section{Statistical analyses}

In this study, data of continuous variables are presented as the median and standard deviation. We performed statistical comparisons using the $\chi^{2}$ test for categorical variables and the Mann-Whitney $U$-test for continuous variables. In addition, we compared the incidence of delayed bleeding between groups using Fisher's exact probability test. Factors associated with delayed bleeding were assessed by the univariate analysis using the $\chi^{2}$ test and Mann-Whitney $U$-test. We considered $\mathrm{p}<0.05$ as indicating statistical significance. All statistical analyses were performed using the Excel statistics 2012 software program (Social Survey Research Information, Tokyo, Japan).

\section{Results}

\section{Patient and lesion characteristics}

We observed no marked difference in the patient age or sex ratio between the groups (Table 1,2). The prevalence of diabetes mellitus was higher in the VPZ group than in the PPI group ( $\mathrm{p}=0.007)$. In both groups, the two primary reasons for receiving antithrombotic therapy were ischemic heart diseases and cerebrovascular diseases. In addition, the most commonly used antithrombotic agents were antiplatelet monotherapy in both groups (PPI: 65\%; VPZ: 49\%, p=0.07), followed by antiplatelet dual therapy (PPI: 14\%; VPZ: $25 \%$, 
Table 2. Lesion-based Characteristics.

\begin{tabular}{llccc}
\hline \multicolumn{1}{c}{ Tumor characteristics } & & $\begin{array}{c}\text { PPI group } \\
101 \text { lesions }\end{array}$ & $\begin{array}{c}\text { VPZ group } \\
90 \text { lesions }\end{array}$ & $\mathrm{p}$ \\
\hline Tumor location, $\mathrm{n}(\%)$ & Body & $66(65)$ & $49(54)$ & 0.12 \\
& Antrum & $35(35)$ & $41(46)$ & \\
Specimen size, median $\pm \mathrm{SD}, \mathrm{mm}$ & & $38 \pm 15$ & $36 \pm 14$ & 0.58 \\
Macroscopic type, n $(\%)$ & Elevated & $60(59)$ & $43(48)$ & 0.1 \\
& Depressed & $41(41)$ & $46(51)$ & \\
Pathological depth, n $(\%)$ & Recurrence & $0(0)$ & $1(1)$ & \\
& No tumor & $1(1)$ & $0(0)$ & 0.02 \\
& Adenoma & $12(12)$ & $6(6.6)$ & \\
& pT1a & $70(69)$ & $78(87)$ & \\
& pT1b & $18(18)$ & $6(6.6)$ & \\
\hline
\end{tabular}

U: upper stomach, M: middle stomach, L: lower stomach, SD: standard deviation

Table 3. Treatment Outcomes of ESD.

\begin{tabular}{llccc}
\hline \multicolumn{1}{c}{ ESD result per patient } & & PPI group & VPZ group & p \\
& & 71 patients & 59 patients & \\
\hline Curability, n (\%) & Curative & $54(76)$ & $53(90)$ & 0.04 \\
& Noncurative & $17(24)$ & $6(10)$ & \\
Perforation during ESD, n (\%) & & $2(2.8)$ & $1(1.6)$ & 0.67 \\
Ulcer protection & None & $51(72)$ & $43(73)$ & 0.89 \\
& Clip closure & $10(14)$ & $15(25)$ & 0.1 \\
& PGA & $10(14)$ & $1(2)$ & 0.01 \\
Hb drop after ESD, g/dL (average, range) & & 0.9 & 0.95 & 0.8 \\
& & $(-2.5-7.9)$ & $(-2.6-9.1)$ & \\
Hemostasis during second-look EGD, n (\%) & & $9(13)$ & $11(19)$ & 0.34 \\
Overall delayed bleeding after ESD & & 13 events & 18 events & 0.10 \\
& & $(18 \%)$ in & $(31 \%)$ in & \\
Delayed bleeding after 2 days of ESD, n (\%) & & 9 patients & 17 patients & \\
Blood transfusion, $\mathrm{n}(\%)$ & & $12(17)$ & $8(14)$ & 0.59 \\
\hline
\end{tabular}

PGA: polyglycolic acid sheet, PPI: proton-pump inhibitor, VPZ: vonoprazan, EGD: esophagogastroduodenoscopy, ESD: endoscopic submucosal dissection, Hb: hemoglobin

$\mathrm{p}=0.1$ ), anticoagulant monotherapy (PPI: 15\%; VPZ: 19\%), and the combination of antiplatelet and anticoagulant therapies (PPI: 6\%; VPZ: 7\%). We observed no marked difference in the number of lesions resected during a single ESD session or the median diameter of the specimen removed by ESD between the groups. However, in the PPI group, more lesions had submucosal invasion than in the VPZ group (pT $1 \mathrm{~b} ; 18 \%$ vs. $6.6 \%)$.

\section{Treatment outcomes}

Table 3 shows the results of ESD for each patient. Based on the histopathological evaluation of the resected specimens, more patients in the VPZ group (90\%) were considered to have achieved curative resection than in the PPI group $(76 \%)$. In both groups, no ulcer protection was performed in $>70 \%$ of patients; however, ulcer protection by covering with a PGA sheet was performed in 10 (14\%) patients in the PPI group and $1(2 \%)$ patient in the VPZ group. During the second-look endoscopy performed on the day after ESD, $9(13 \%)$ patients in the PPI group and 11
(19\%) in the VPZ group underwent prophylactic haemostasis for the vessels remaining at the ESD ulcer.

\section{Primary endpoint: delayed bleeding after ESD}

Overall delayed bleeding was observed 13 times (18\%) in 9 patients (twice in 2 patients, 3 times in 1 patient) in the PPI group and 18 times (31\%) in 17 patients (twice in 1 patient) in the VPZ group. Delayed bleeding from day 2 until 8 weeks after ESD occurred 12 times (17\%) in 9 patients in the PPI group and 8 times (14\%) in 8 patients in the VPZ group. The number of cases of overall delayed bleeding and bleeding that occurred from day 2 until 8 weeks after ESD did not show significant differences between the groups.

The timing of delayed bleeding in the two groups is shown in Fig. 2. On days 0 and 1, 11 patients had bleeding (10 patients in VPZ, 1 patient in PPI group). Among the 10 patients in the VPZ group, only 1 had undergone endoclip closure, and bleeding was observed between the endoclips during second-look endoscopy. The patient in the PPI group had received PGA shielding; however, bleeding occurred be- 


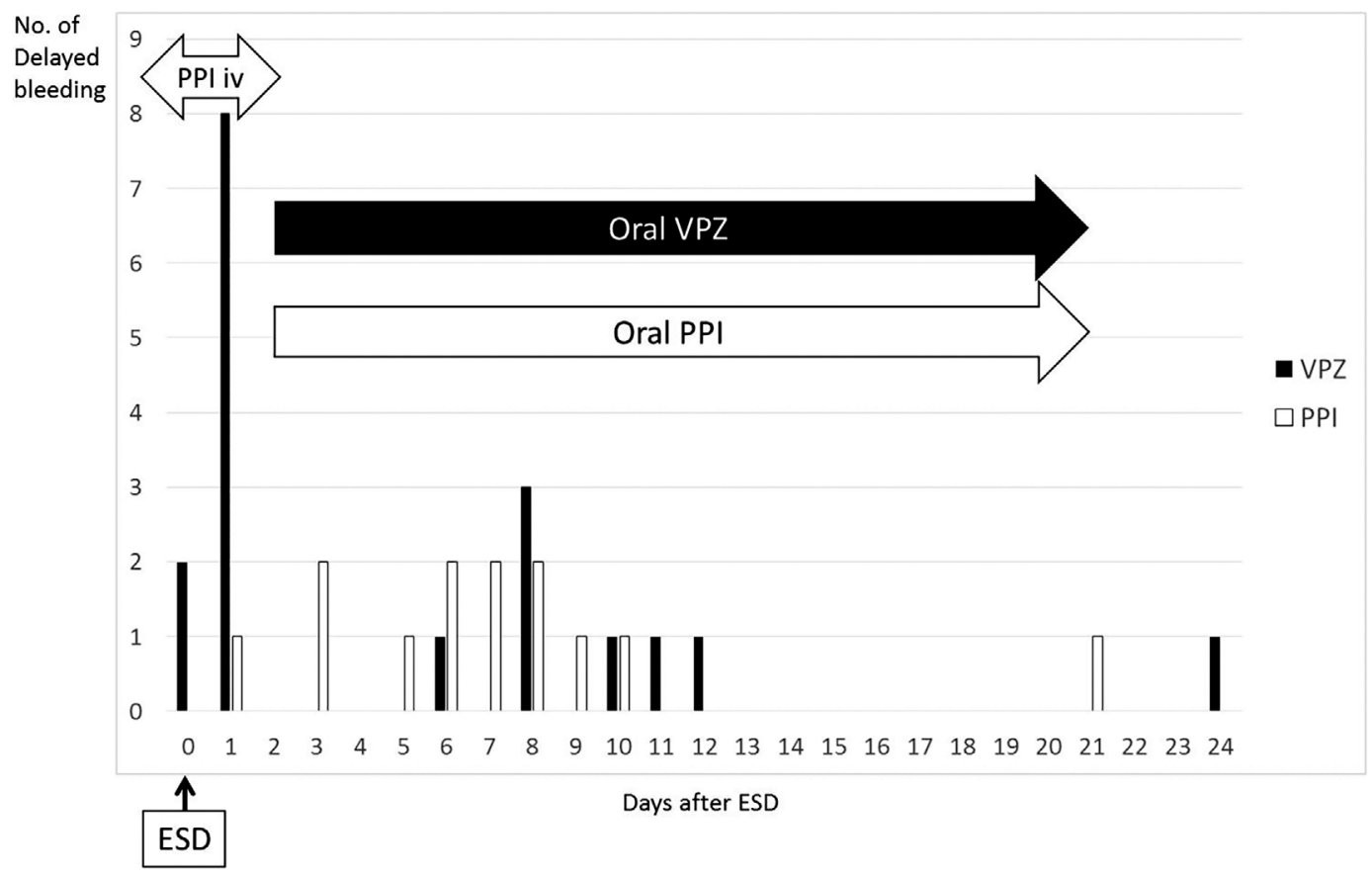

Figure 2. The number of times and days on which emergency endoscopy was required after endoscopic submucosal dissection (ESD). PPI: proton-pump inhibitor, VPZ: vonoprazan

Table 4. Incidence of Bleeding after ESD in the Treatment Groups according to Each Variable.

\begin{tabular}{llccc}
\hline & & PPI group & VPZ group & \\
& & 71 patients & 59 patients & \\
\hline Tumor location & Body & $5 / 40(13 \%)$ & $6 / 32(19 \%)$ & 0.53 \\
& Antrum & $4 / 31(13 \%)$ & $11 / 27(41 \%)$ & 0.06 \\
Number of tumors & Single & $6 / 53(11 \%)$ & $9 / 40(23 \%)$ & 0.22 \\
& Multiple & $3 / 18(17 \%)$ & $8 / 19(42 \%)$ & 0.20 \\
Curability & Curative & $7 / 54(13 \%)$ & $14 / 53(26 \%)$ & 0.15 \\
& Noncurative & $2 / 17(12 \%)$ & $3 / 6(50 \%)$ & 0.14 \\
\hline
\end{tabular}

ESD: endoscopic submucosal dissection, VPZ: vonoprazan, PPI: proton-pump inhibitor

neath the PGA sheet. Therefore, haemostasis was performed by removing the PGA sheet followed by coagulation with haemostatic forceps. This patient also had recurrent delayed bleeding on days 9 and 10. Overall, the last bleeding event was observed on day 24, and all events were observed within 4 weeks after ESD.

\section{Secondary outcomes}

In the subgroup analyses (Table 4), no significant difference was observed among the incidence of bleeding in terms of the tumour location, number of tumours, and curability of ESD between the groups.

In the subgroup analyses comparing cases without ulcer protection (Table 5), the prevalence of diabetes mellitus was higher $(\mathrm{p}=0.006)$ and the ratio of cases taking antiplatelet monotherapy was lower in the VPZ group than in the PPI group $(\mathrm{p}=0.02)$. The numbers of cases of overall delayed bleeding and bleeding that occurred from day 2 until 8 weeks after ESD were higher in the VPZ group than in the PPI group but without a significant difference.

\section{Discussion}

This study assessed the incidence of delayed bleeding among patients who underwent ESD with continuous antithrombotic agents. The occurrence of delayed bleeding did not exhibit a marked difference between patients using VPZ or traditional PPI for ulcer treatment after ESD. To our knowledge, this is the first study to compare the incidence of delayed bleeding after ESD using VPZ or traditional PPI in patients with continuous antithrombotic agents. This study suggests that despite using a potent antacid agent, such as VPZ, the incidence of delayed bleeding after ESD in patients with continuous use of antithrombotic agents remains high.

Several studies have reported that continuous aspirin or 
Table 5. Subgroup Analyses: Comparison among Cases without Ulcer Protection.

\begin{tabular}{|c|c|c|c|c|}
\hline & & $\begin{array}{l}\text { PPI group } \\
51 \text { patients }\end{array}$ & $\begin{array}{l}\text { VPZ group } \\
43 \text { patients }\end{array}$ & $\mathrm{p}$ \\
\hline Age, year, median \pm SD & & $76 \pm 7$ & $76 \pm 7$ & 0.8 \\
\hline Sex, male, $\mathrm{n}(\%)$ & & $39(76)$ & $38(88)$ & 0.13 \\
\hline \multirow[t]{3}{*}{ Comorbidity, n (\%) } & Hypertension & $41(80)$ & $33(77)$ & 0.66 \\
\hline & Diabetes mellitus & $5(10)$ & $14(33)$ & 0.006 \\
\hline & Renal failure on hemodialysis & $0(0)$ & $0(0)$ & - \\
\hline \multirow[t]{4}{*}{ Reasons for antithrombotic therapy, n (\%) } & Ischemic heart disease & $11(22)$ & $12(30)$ & 0.47 \\
\hline & Arrhythmia & $7(14)$ & $6(14)$ & 0.97 \\
\hline & Cerebrovascular disease & $13(25)$ & $16(37)$ & 0.22 \\
\hline & Others & $5(10)$ & $2(5)$ & 0.34 \\
\hline \multirow[t]{4}{*}{ Type of antithrombotic agents, n (\%) } & Antiplatelet monotherapy & $40(78)$ & $23(53)$ & 0.02 \\
\hline & Antiplatelet dual therapy & $6(12)$ & $10(23)$ & 0.14 \\
\hline & Anticoagulant monotherapy & $6(12)$ & $6(14)$ & 0.75 \\
\hline & Combination of antiplatelet and anticoagulant & $1(2)$ & $4(9)$ & 0.1 \\
\hline \multirow[t]{2}{*}{ Number of tumors, n (\%) } & 1 & $40(78)$ & $28(65)$ & 0.15 \\
\hline & $2-6$ & $11(22)$ & $15(35)$ & \\
\hline \multirow[t]{2}{*}{ Curability, n (\%) } & Curative & $40(78)$ & $38(88)$ & 0.20 \\
\hline & Noncurative & $11(22)$ & $5(12)$ & \\
\hline Overall delayed bleeding after ESD, n (\%) & & $7(14)$ & $14(33)$ & 0.052 \\
\hline Delayed bleeding after 2 days of ESD, $\mathrm{n}(\%)$ & & $7(14)$ & $6(20)$ & 0.97 \\
\hline
\end{tabular}

SD: standard deviation, n: number, PPI: proton-pump inhibitor, VPZ: vonoprazan

antiplatelet agent use during ESD exerted no effect on the ESD outcomes and delayed bleeding under the use of a conventional PPI (8-10). However, while the antiplatelet usage was not determined to be an independent risk factor of delayed bleeding in a multivariate analysis, Lim et al. reported that the incidence of bleeding was $11.6 \%$ in the continuous group, compared with $5.2 \%$ in the no antiplatelet group and $5.9 \%$ in the discontinuation group (8). In addition, Tounou et al. reported that the incidence was $35.5 \%, 15.5 \%$, and $1.1 \%$ in the dual antiplatelet, single antiplatelet, and no antiplatelet groups, respectively (10). Furthermore, our previous study reported that thrombotic events occurred only in the discontinuation group (1.6\%) (11). Thus, gastric ESD without cessation of antithrombotic agents may help prevent thrombosis in high-risk patients; however, the high incidence of delayed bleeding should be considered.

Among previous studies comparing the efficacy between VPZ and traditional PPI for the ESD ulcer treatment, five studies included a few patients with continuous antithrombotic agents $(17,19-21,24)$. In these studies, the ratio of patients with continuous antithrombotic agents was small (6.8-22.5\%), and only Kagawa et al. reported a substantial difference in delayed bleeding (24). In their retrospective analysis, the delayed bleeding rate was $1.3 \%$ in patients treated with VPZ compared with $10 \%$ in those treated with PPI (24). Furthermore, their study enrolled only $17 \%$ of patients with antithrombotic agents but also reported that the usage of an antithrombotic agent was a considerable factor for delayed bleeding (24). In our study, we only enrolled patients who received continuous antithrombotic agents during ESD in order to elucidate the preventive effect of using VPZ in a group with a high risk of delayed bleeding. However, the delayed bleeding rate was high in both the VPZ and PPI groups, with no significant difference. Despite patients being treated with an intravenous PPI for the first two days, the delayed bleeding rate observed from day 2 until 8 weeks after ESD did not show any marked difference between the groups.

Typically, delayed bleeding is observed during the first 2 days of ESD; however, it has been reported that, in patients taking antithrombotic agents, delayed bleeding can occur at a later point after ESD (1-2 weeks later) $(6,29)$. In the present study, the number of patients with delayed bleeding showed a bimodal distribution, with peaks at the first 2 days and around 1 week. The exact reason for the increased incidence of bleeding at days 0-1 in the VPZ group is unknown. Since oral feeding is not yet restarted during this period, incomplete prophylactic coagulation of vessels after ESD, reflux of bile acid, or other unknown factors are possible causes. In addition, as the median duration of admission was 5 days, some patients experienced delayed bleeding after being discharged from the hospital. Ideally, cessation of antithrombotic agents during this period would be beneficial to minimize the risk of bleeding; however, the risk of thrombotic events is also expected to increase. Thus, patients undergoing ESD with continuous antithrombotic agents should be informed of their high risk of bleeding for the first two weeks after ESD.

This study has some limitations. First, it was a singlecentre, retrospective study with a rather small number of patients. Thus, a substantial bias for the selection of VPZ or PPI for each patient cannot be denied. The numbers of diabetes patients, lesions with submucosal invasion, and cases with PGA differed between the groups. However, these fac- 
tors have not been shown to be definitively related to bleeding in previous large-scale studies, and ulcer protection procedures are still relatively new and not yet standardised. The subgroup analysis among cases with no ulcer protection also showed no significant difference in the rate of delayed bleeding between the groups. The sample size may have been too small to perform a propensity score matching analysis, and further prospective studies are needed. Nevertheless, we enrolled the highest number of patients to date undergoing ESD with continuous antithrombotic agents. Second, the kind of PPI was not unified. Three types of oral PPI (rabeprazole, lansoprazole or esomeprazole) were available for use in our hospital. There are no studies that have shown any of these PPIs to be inferior to the others with respect to healing ESD ulcers, and the administration of any PPI is recommended for the treatment of ESD ulcers (4). Third, intravenous PPI was used for the first two days in both groups. Only omeprazole is available for intravenous use in our hospital, and it is our routine practice to administer intravenous PPI until oral feeding is resumed. No study has yet demonstrated the superiority of VPZ over intravenous PPI. Further studies are warranted to clarify which treatment is best for reducing the incidence of bleeding among patients continuing antithrombotics.

In conclusion, this study showed that even with a potent antacid agent, such as VPZ, the incidence of delayed bleeding was high among patients undergoing ESD who were receiving continuous antithrombotic agents.

All patients provided their written informed consent for ESD under continuous administration of antithrombotic agents.

This study protocol was approved by the Ethics Committee of our hospital.

The authors state that they have no Conflict of Interest (COI).

\section{References}

1. Ono H, Yao K, Fujishiro M, et al. Guidelines for endoscopic submucosal dissection and endoscopic mucosal resection for early gastric cancer. Dig Endosc 28: 3-15, 2016.

2. Hasuike $\mathrm{N}$, Ono $\mathrm{H}$, Boku $\mathrm{N}$, et al. A non-randomized confirmatory trial of an expanded indication for endoscopic submucosal dissection for intestinal-type gastric cancer (cT1a): the Japan Clinical Oncology group study (JCOG0607). Gastric Cancer 21: 114-123, 2018.

3. Takizawa K, Oda I, Gotoda T, et al. Routine coagulation of visible vessels may prevent delayed bleeding after endoscopic submucosal dissection: an analysis of risk factors. Endoscopy 40: 179-183, 2008.

4. Fujishiro M, Iguchi M, Kakushima N, et al. Guidelines for endoscopic management of non-variceal upper gastrointestinal bleeding. Dig Endosc 28: 363-378, 2016.

5. Ono S, Fujishiro M, Yoshida N, et al. Thienopyridine derivatives as risk factors for bleeding following high risk endoscopic treatments: safe treatment on antiplatelets (STRAP) study. Endoscopy 47: 632-637, 2015.

6. Yoshio T, Nishida T, Kawai N, et al. Gastric ESD under heparin replacement at high-risk patients of thromboembolism is techni- cally feasible but has a high risk of delayed bleeding: Osaka University ESD Study Group. Gastroenterol Res Pract 2013: 365830, 2013.

7. Cho SJ, Choi IJ, Kim CG, et al. Aspirin use and bleeding risk after endoscopic submucosal dissection in patients with gastric neoplasms. Endoscopy 44: 114-121, 2012.

8. Lim JH, Kim SG, Kim JW, et al. Do antiplatelets increase the risk of bleeding after endoscopic submucosal dissection of gastric neoplasms? Gastrointest Endosc 75: 719-727, 2012.

9. Sanomura Y, Oka S, Tanaka S, et al. Continued use of low-dose aspirin does not increase the risk of bleeding during or after endoscopic submucosal dissection for early gastric cancer. Gastric Cancer 17: 489-496, 2014.

10. Tounou S, Morita Y, Hosono T. Continuous aspirin use does not increase post-endoscopic dissection bleeding risk for gastric neoplasms in patients on antiplatelet therapy. Endosc Int Open 3: E31-E38, 2015.

11. Igarashi K, Takizawa K, Kakushima N, et al. Should antithrombotic therapy be stopped in patients undergoing gastric endoscopic submucosal dissection? Surg Endosc 31: 1746-1753, 2017.

12. Furuhata T, Kaise M, Hoteya $S$, et al. Postoperative bleeding after gastric endoscopic submucosal dissection in patients receiving antithrombotic therapy. Gastric Cancer 20: 207-214, 2017.

13. Fujimoto K, Fujishiro M, Kato M, et al.; Japan Gastroenterological Endoscopy Society. Guidelines for gastroenterological endoscopy in patients undergoing antithrombotic treatment. Dig Endosc 26: 1-14, 2014.

14. Veitch AM, Vanbiervliet G, Gershlick AH, et al. Endoscopy in patients on antiplatelet or anticoagulant therapy, including direct oral anticoagulants: British Society of Gastroenterology (BSG) and European Society of Gastrointestinal Endoscopy (ESGE) guidelines. Endoscopy 48: 385-402, 2016.

15. Sakurai Y, Mori Y, Okamoto H, et al. Acid-inhibitory effects of vonoprazan $20 \mathrm{mg}$ compared with esomeprazole $20 \mathrm{mg}$ or rabeprazole $10 \mathrm{mg}$ in healthy adult male subjects - a randomized open-label cross-over study. Aliment. Pharmacol. Ther 42: 719$730,2015$.

16. Ishii Y, Yamada H, Sato $T$, et al. Effects of Vonoprazan compared with esomeprazole on the healing of artificial postendoscopic submucosal dissection ulcers: a prospective, multicenter, two-arm randomized controlled trial. Gastroenterol Res Pract 18: 1615092, 2018.

17. Hirai A, Takeuchi T, Takahashi R, et al. Comparison of the effects of vonoprazan and lansoprazole for treating endoscopic submucosal dissection-induced artificial ulcers. Dig Dis Sci 63: 974-981, 2018 .

18. Yamasaki A, Yoshio T, Muramatsu Y, et al. Vonoprazan is superior to rabeprazole for healing endoscopic submucosal dissection induced ulcers. Digestion 97: 170-176, 2018.

19. Shimozato A, Sasaki M, Ogasawara N, et al. Risk factors for delayed ulcer healing after endoscopic submucosal dissection of gastric neoplasms. J Gastrointestin Liver Dis 26: 363-368, 2017.

20. Horikawa Y, Mizutamari H, Mimori N, et al. Short-term efficacy of potassium-competitive acid blocker following gastric endoscopic submucosal dissection: a propensity score analysis. Scand J Gastroenterol 53: 243-251, 2018.

21. Tsuchiya I, Kato Y, Tanida E, et al. Effect of vonoprazan on the treatment of artificial gastric ulcers after endoscopic submucosal dissection: prospective randomized controlled trial. Dig Endosc 29: 576-583, 2017.

22. Takahashi K, Sato Y, Kohisa J, et al. Vonoprazan $20 \mathrm{mg}$ vs lansoprazole $30 \mathrm{mg}$ for endoscopic submucosal dissection-induced gastric ulcers. World J Gastrointest Endosc 8: 716-722, 2016.

23. Maruoka D, Arai M, Kasamatsu S, et al. Vonoprazan is superior to proton pump inhibitors in healing artificial ulcers of the stomach post-endoscopic submucosal dissection: a propensity score- 
matching analysis. Dig Endosc 29: 57-64, 2017.

24. Kagawa $T$, Iwamuro $M$, Ishikawa $S$, et al. Vonoprazan prevents bleeding from endoscopic submucosal dissection-induced gastric ulcers. Aliment Pharmacol Ther 44: 583-591, 2016.

25. Ichida T, Ueyama S, Eto T, Kusano F, Sakai Y. Randomized controlled trial comparing the effects of Vonoprazan plus rebamipide and esomeprazole plus rebamipide on gastric ulcer healing induced by endoscopic submucosal dissection. Intern Med 58: 159166, 2019.

26. Hamada K, Uedo N, Tonai $\mathrm{Y}$, et al. Efficacy of vonoprazan in prevention of bleeding from endoscopic submucosal dissectioninduced gastric ulcers: a prospective randomized phase II study. J Gastroenterol 54: 122-130, 2019.

27. Ono H, Hasuike N, Inui T, et al. Usefulness of a novel electrosur- gical knife, the insulation-tipped diathermic knife-2, for endoscopic submucosal dissection of early gastric cancer. Gastric Cancer 11: 47-52, 2008

28. Japanese Gastric Cancer Association. Japanese gastric cancer treatment guidelines 2014 (ver. 4). Gastric Cancer 20: 1-19, 2017.

29. Kawata N, Ono H, Takizawa K, et al. Efficacy of polyglycolic acid sheets and fibrin glue for prevention of bleeding after gastric endoscopic submucosal dissection in patients under continued antithrombotic agents. Gastric Cancer 21: 696-702, 2018.

The Internal Medicine is an Open Access journal distributed under the Creative Commons Attribution-NonCommercial-NoDerivatives 4.0 International License. To view the details of this license, please visit (https://creativecommons.org/licenses/ by-nc-nd/4.0/).

(C) 2019 The Japanese Society of Internal Medicine Intern Med 58: 2759-2766, 2019 